\title{
Effect of Creep Stress on the Microstructure of $9-12 \%$ Cr Steel for Rotor Materials
}

\author{
Jiling Dong, ${ }^{1,2}$ Yinsheng $\mathrm{He}^{2}$ Minsoo Kim, ${ }^{3}$ and Keesam Shin ${ }^{2, \star}$ \\ ${ }^{1}$ School of Metallurgy and Materials Engineering, Chongqing University of Science and Technology, \\ Chongqing 401-331, China \\ ${ }^{2}$ School of Nano \& Advanced Materials Engineering, Changwon National University, Changwon 641-773, Korea \\ ${ }^{3}$ Doosan Heavy Industries \& Construction Co. Ltd., Changwon 642-792, Korea
}

\begin{abstract}
High-chromium heat-resistant steel has been widely used as the key material to improve the condition of steam pressure and temperature in the modern high-efficiency power plants. Despite the use of the steel above $550^{\circ} \mathrm{C}$ for several decades, its major failure is owing to the creep fracture. In this study, the effect of creep stress on the microstructure in $9-12 \% \mathrm{Cr}$ steel has been investigated microscopically, and it is clarified that the creep stress enhances precipitation of Laves phase and influences the lath width and dislocation density in lath interior.
\end{abstract}

Key words: $9-12 \% \mathrm{Cr}$, microstructure, stress, EBSD, mechanical property, lifetime assessment

\section{INTRODUCTION}

For $9-12 \%$ Cr steels, widely used for gas turbine compressor, steam turbine/rotor, and casing (Klotz et al., 1999), the stability of the microstructure is one of the key requirements for industrial applications, which is usually achieved by heat treatments, including austenitizing, quenching, and tempering (at $680-780^{\circ} \mathrm{C}$; Janovec et al., 1998). It is well known that Laves phase in $9-12 \%$ Cr steels contributes to the precipitation strengthening at high temperatures but induces embrittlement at low temperatures (Fujita, 1990). In this study, stress effect on the precipitation behavior of Laves phase, lath width, and dislocation density during creep rupture test has been investigated. For the analysis, the following specimens were examined: (1) as-tempered (AT hereafter) specimen, (2) the grip (GP hereafter) of the creep specimen (stress-free thermal aging), (3) the gauge part near the fracture surface (microstructural evolution under stress, GG hereafter), and (4) $6 \mathrm{~mm}$ from fracture surface (6FFS hereafter).

\section{Experimental Procedure}

The chemical composition of the specimens was $0.12 \mathrm{C}-$ $0.75 \mathrm{Ni}-10.5 \mathrm{Cr}-1.0 \mathrm{Mo}-1.0 \mathrm{~W}-0.18 \mathrm{~V}-0.05 \mathrm{Nb}-0.05 \mathrm{~N}$ (wt $\%$ ). Creep rupture tests were performed at 593, 621, and $649^{\circ} \mathrm{C}$ under stress from 110 to $310 \mathrm{MPa}$. After creep rupture test, the microstructure was observed for the specimen with the rupture time of $5,819.3 \mathrm{~h}$ at $649^{\circ} \mathrm{C}$ under a constant load corresponding to the stress of $110 \mathrm{MPa}$. For specimens of the optical microscope $(\mathrm{OM})$ and scanning electron microscope (SEM) observation, Vilella's reagent $(100 \mathrm{~mL}$ ethanol $+1 \mathrm{~g}$ picric acid $+5 \mathrm{~mL} \mathrm{HCl}$ ) was used as an etchant. SEM back-scattered electron images (BEI) in combination

() MICROSCOPY SOCIETY OF AMERICA 2013

*Corresponding author. E-mail: keesam@changwon.ac.kr with transmission electron microscopy (TEM) were used for measurement of the size distribution and area fraction of the second phase. Thin foils for TEM analysis were electropolished with an electrolyte of $95 \%$ acetic acid $+5 \%$ perchloric acid. The specimens for electron back-scatter diffraction (EBSD) maps were polished with colloidal silica, and then the EBSD maps were acquired from the longitudal direction.

\section{Results AND Discussion}

\section{$\mathrm{OM}$ and SEM Analysis}

The microstructure of overall specimens after normalizing and tempering was tempered martensite. After creep rupture test, typical tempered martensite was also observed, but coarsening of lath and recovery resulting in the formation of subgrains occurred. No big difference was found between these specimens from OM analysis.

Figures $1 \mathrm{a}$ and $1 \mathrm{~b}$ show the SEM BEI images on the Laves phase formation in the 6FFS and GP specimens. Generally, it can be seen that the Laves phase was nucleated mainly in prior austenite grain boundaries and lath martensite boundaries, and slightly larger precipitates were formed uniformly in the matrix under the creep stress loading (Fig. 1b) than those at the stress unloaded state (Fig. 1a). Accordingly, the creep stress effect on the Laves phase is clearly shown in these figures. Quantitative analysis for the size and number density of the Laves phase has been made in both specimens, as shown in Table 1. These values indicate that creep stress enhances the number density of Laves phase obviously. Meanwhile, the average size of Laves phase in the 6FFS specimen is slightly larger.

Creep damage was also investigated on longitudinal cross-sections. One broken half of the creep specimen was cut into two halves, and then polished with colloidal silica. A high number of elongated cavities (along stress direction) 

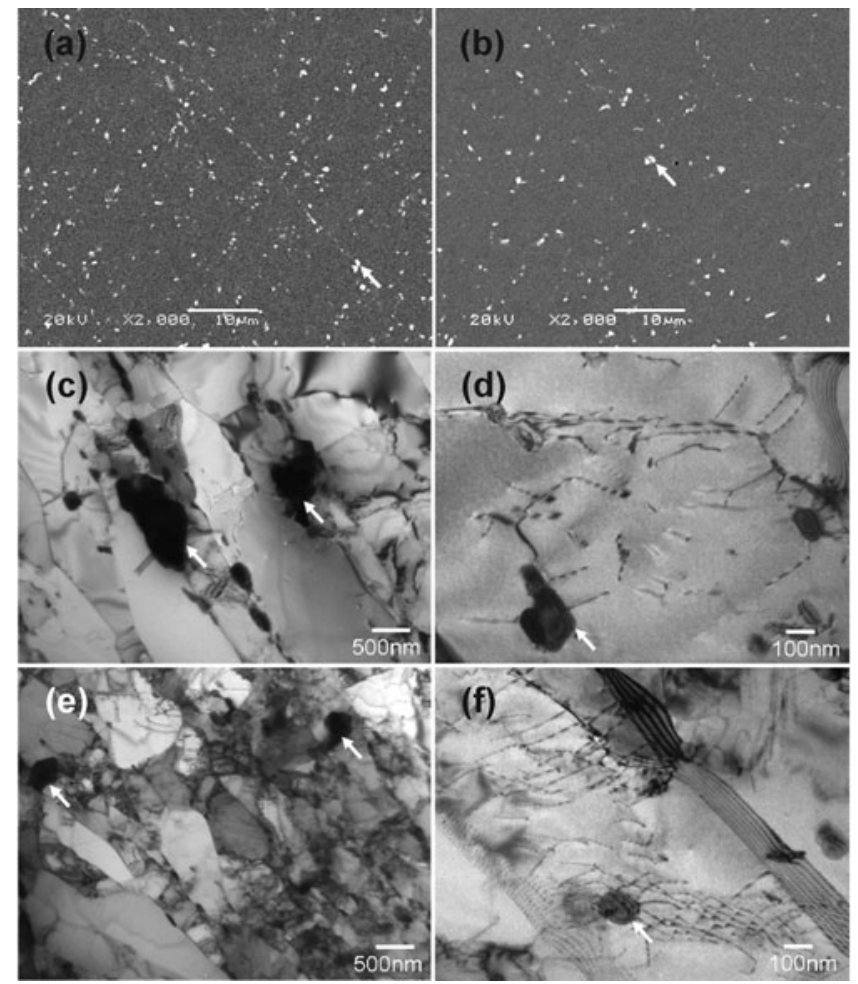

Figure 1. a, b: SEM BEI, and (c)-(f) TEM micrographs of: (a), (c), and (d) -6FFS and (b), (e), and (f) - GP specimens. The Laves phase is highlighted by white arrows. SEM, scanning electron microscope; BEI, back-scattered electron images; TEM, transmission electron microscopy; 6FFS, $6 \mathrm{~mm}$ from fracture surface; GP, grip.

were observed near the fracture surface, which was seldom observed at the GP part. The cavity formation was attributed to stress concentration at triple points and precipitates on the boundaries, and thus it is important to investigate the boundaries in this material under stress conditions.

\section{EBSD Analysis}

In this study, EBSD inverse pole figure (IPF) maps of the specimens of AT, 6FFS, and GP revealed a typical martensitic matrix with blocks and packets (Figs. 2a, 2c, 2d), but showed a wider lath width after creep rupture test (Figs. 2b, $2 \mathrm{~b} 1)$. The shape of these grains is very elongated in the AT specimen and less elongated in the GP specimen. Meanwhile, after creep rupture test, EBSD measurements of the GG part revealed a matrix with many round-shaped grains
(Figs. 2b, 2b1). This is because subgrain evolution occurred both upon thermal aging (GP) and creep deformation (GG), but mostly during the fast deformation.

According to misorientation angle histograms (Fig. 3), while the boundaries between small grains in AT state and 6FFS have misorientation angles, typical of those between martensite variants from the same parent austenite grain, this might not be so clear next to the fracture surface. This may be due to the dynamic recrystallization occurring during creep rupture test.

\section{TEM Analysis}

TEM is used for the characterization of $\mathrm{M}_{23} \mathrm{C}_{6}$ carbides, and also lath width and dislocation density. The growth rate of lath width and the recovery rate of dislocation are kept slow in 6FFS after creep rupture test (Table 1).

As shown in Figures $1 \mathrm{c}$ and 1e, slightly darker images of the Laves phase are observed in the 6FFS than in the GG part. In addition, these figures also indicate that creep stress enhances the Laves phase precipitation, which is attributed to the high density of dislocation induced by the high stress at or near the GP part that can provide room for W atoms, which in turn can act as nucleation for Laves phase (Figs. 1e, 1f). The quantitative analysis results (Table 1) indicate that the creep stress accelerates the Laves phase and $\mathrm{M}_{23} \mathrm{C}_{6}$ precipitation, but lowers dislocation density.

\section{Mechanical Property and Life Evaluation}

Results of creep rupture test are shown in Figure $4 \mathrm{a}$ as a function of creep rupture time. In addition to describing the combined effect of temperature $T$ and time $t$, LarsonMiller parameter $P=T(C+\log t)$ is generally used (May, 1981; Machida \& Yoshioka, 2002) to evaluate the hightemperature behaviors and lifetime. The earlier study (Yang et al., 2004) reported that $C$-value in Larson-Miller parameter was mainly a function of carbon content without significant effect of alloying elements. On the basis of the reference (Yang et al., 2004), the $C$-value among LarsonMiller parameter in this study is taken as 20.4, owing to $0.12 \mathrm{wt} \%$ of carbon content.

The relationships between stress and $P$ and between $P_{t}$ and $\log \sigma$ are shown in Figures 4b and 4c. It is known that during the creep rupture, there is the following relationship between $P\left(P_{t}\right)$ and stress $(\sigma)$, and also the residual $P$ parameter $\left(P_{r}\right)$ and residual life $\left(t_{r}\right)$ can be derived (May, 1981):

Table 1. Quantitative Data of $6 \mathrm{~mm}$ from Fracture Surface (6FFS) and Grip (GP) Specimens.

\begin{tabular}{|c|c|c|c|c|c|c|c|}
\hline \multirow[b]{2}{*}{ Item } & \multirow[b]{2}{*}{$\begin{array}{l}\text { Grain Size } \\
\qquad(\mu \mathrm{m})\end{array}$} & \multicolumn{2}{|c|}{ Laves Phase } & \multicolumn{2}{|c|}{$\mathrm{M}_{23} \mathrm{C}_{6}$} & \multirow[b]{2}{*}{$\begin{array}{l}\text { Lath Width } \\
\qquad(\mu \mathrm{m})\end{array}$} & \multirow[b]{2}{*}{$\begin{array}{l}\text { Dislocation Density } \\
\quad\left(\times 10^{14} \mathrm{~m}^{-2}\right)\end{array}$} \\
\hline & & $\begin{array}{l}\text { Size } \\
(\mathrm{nm})\end{array}$ & $\begin{array}{c}\text { Area } \\
\text { Fraction } \\
(\%)\end{array}$ & $\begin{array}{l}\text { Size } \\
(\mathrm{nm})\end{array}$ & $\begin{array}{c}\text { Area } \\
\text { Fraction } \\
(\%)\end{array}$ & & \\
\hline $6 \mathrm{FFS}$ & 66.2 & 389 & 1.18 & 148 & 8.96 & 1.42 & 2.61 \\
\hline GP & 63.3 & 343 & 0.64 & 120 & 3.72 & 0.64 & 4.59 \\
\hline
\end{tabular}




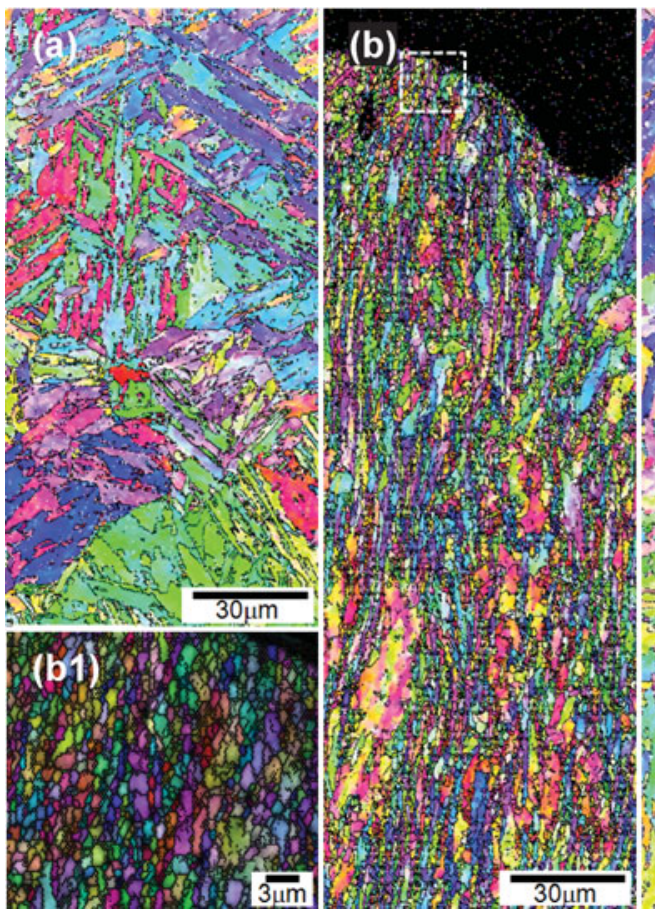

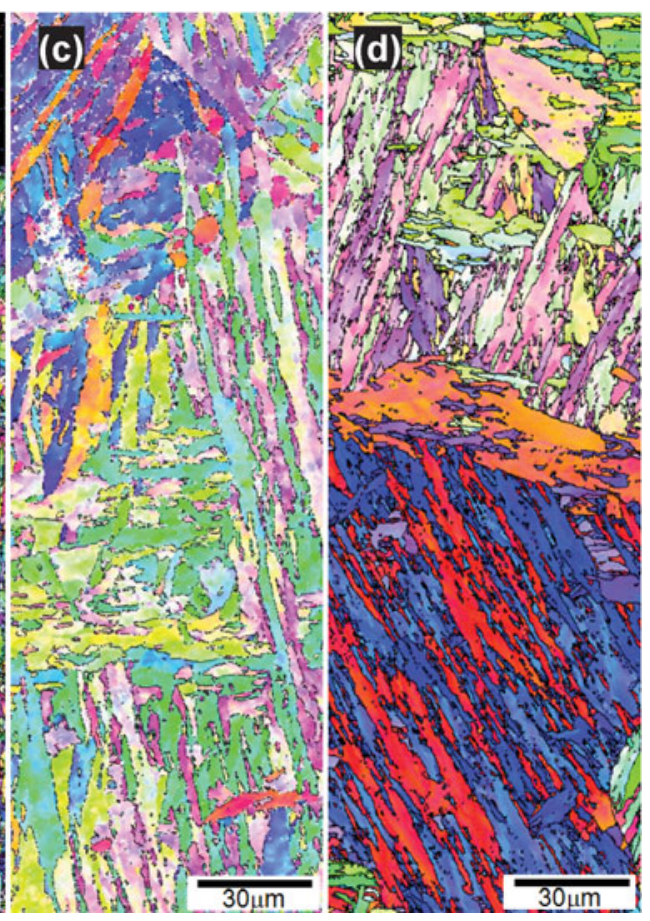

Figure 2. EBSD IPF maps of (a) AT, (b) GG, (c) 6FFS, and (d) GP specimens (b1) is a local magnified figure of (b) marked by a white rectangle. EBSD, electron back-scatter diffraction; IPF, inverse pole figure; AT, as-tempered; GG, gauge; $6 \mathrm{FFS}$, $6 \mathrm{~mm}$ from fracture surface; GP, grip.

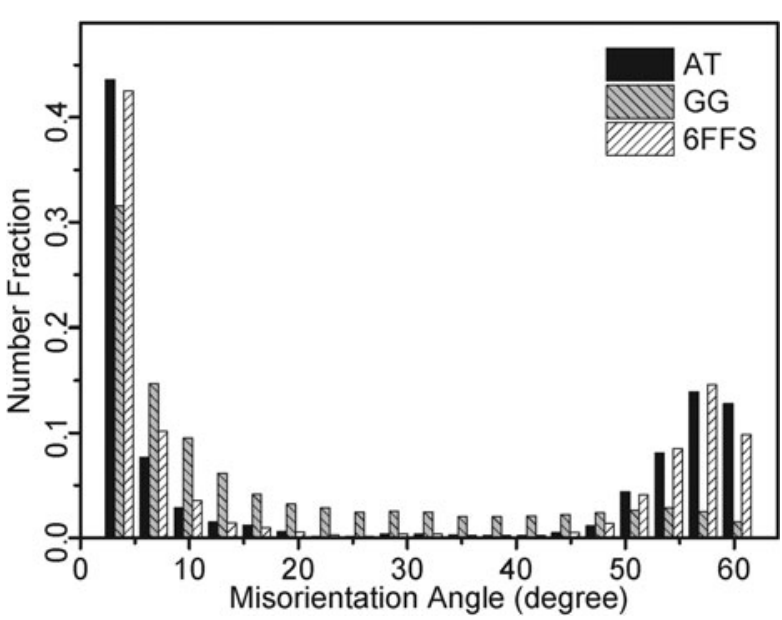

Figure 3. Histogram of misorientation angles in AT, GG, and 6FFS specimens. AT, as-tempered; GG, gauge; 6FFS, $6 \mathrm{~mm}$ from fracture surface.

$$
\begin{aligned}
& P_{t}=K_{1}+K_{2} \log \sigma, \\
& P_{t}=K_{1}+K_{2} \log \sigma-T_{0}\left(C+\log t_{0}\right), \\
& t_{r}=10^{\left(P_{\mathrm{t}}-P_{0}\right) /\left(T_{\mathrm{r}}-C\right)},
\end{aligned}
$$

where $K_{1}$ and $K_{2}$ are two constants, $t_{0}$ is the hours used at temperature $T_{0}$, and Larson-Miller parameter is $P_{0}=$ $T_{0}\left(C+\log t_{0}\right)$. As shown in Figure $4 \mathrm{c}$, the calculated $P$-value has a good linear relationship with $\log \sigma$. In this study, the calculated $K_{1}$ and $K_{2}$ are equal to 34,631 and 6,000, respectively. By using the parameters that are calculated, based on equations (1)-(3), the residual life can be calculated from data of the onsite service condition of the parts.

\section{SUMMARY}

The effects of creep stress on microstructure are as follows:

1. The creep stress enhances the formation of Laves phase, resulting in larger Laves phase under stress loading.
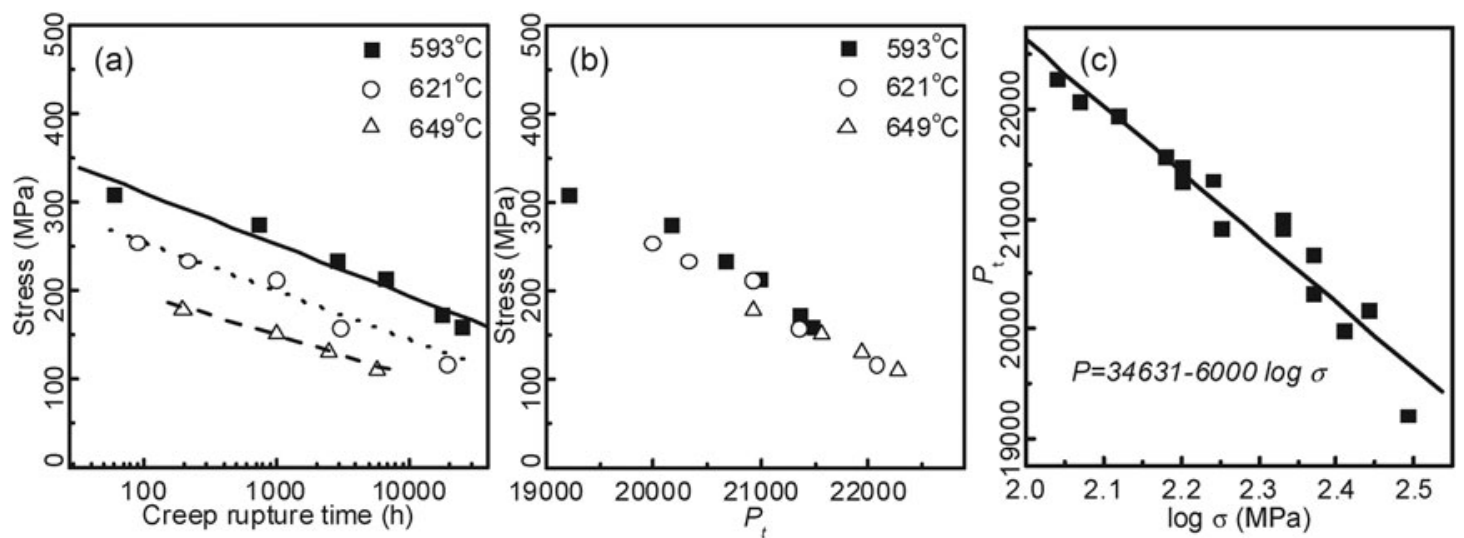

Figure 4. Creep rupture test results (a), relationship between stress and $P_{t}(\mathbf{b})$, and $P_{t}$, and $\log \sigma(\mathbf{c})$. 
2. The growth rate of lath width is higher under stressed condition, but the dislocation density in lath interior is smaller.

3. IPF map is useful and effective for detecting grain and block boundary. A significant change in the substructure of the matrix after creep rupture test was revealed by EBSD measurements, for example, round-shaped subgrains and continuous recrystallization.

4. The service life of the steel can be predicted using the Larson-Miller parameter with the determined $C$-value, and calculated $K_{1}$ and $K_{2}$, which are 20.4, 34,631, and 6,000, respectively.

\section{ACKNOWLEDGMENTS}

This study was funded by the Doosan Heavy Industries \& Construction Co. Ltd. The research was also supported by the National Research Foundation of Korea (NRF) grant funded by the Korea government (MEST, No. 2011-0030803).

\section{REFERENCES}

Fujita, T. (1990). Development of high chromium ferritic steels for ultra super critical power plant. Tetsu to Hagane 76, 1053-1059.

Janovec, J., Svoboda, M. \& Blach, J. (1998). Evolution of secondary phases $12 \% \mathrm{Cr}$ steel during quenching and tempering. Mater Sci Eng A 249, 184-189.

Klotz, U.E., Solenthaler, C., Ernst, P., Uggowitzer, P.J. \& SPEIDEL, M.O. (1999). Alloy compositions and mechanical properties of $9-12 \%$ chromium steels with martensitic-austenitic. Mater Sci Eng A 272, 292-299.

Machida, H. \& Yoshioka, N. (2002). Structural integrity evaluation method for overheating rupture of FBR steam generate tube. Nucl Eng Des 212(2), 183-192.

May, I.L. (1981). Principles of Mechanical Metallurgy. New York: Edward Arnold.

YANG, R.C., Chen, K., Feng, H.X. \& WANG, H. (2004). Determination and application of Larson-Miller parameter for heat resistant steel 12Cr1MoV and 15CrMo. Acta Metall Sin (Engl Lett) 17(4), 471-476. 